\title{
Infusions and decoctions of dehydrated fruits of Actinidia arguta and Actinidia deliciosa: Bioactivity, radical scavenging activity and effects on cells viability
}

\author{
Ana Margarida Silva , Diana Pinto , Iva Fernandes , Tânia Gonçalves Albuquerque , \\ Helena S. Costa
}

Keywords:

Kiwifruit

Kiwiberry

Infusion

Decoction

Phenolic profile

\begin{abstract}
A B S T R A C T
Actinidia deliciosa and $A$. arguta fruits (kiwifruit and kiwiberry, respectively) are an excellent source of bioactive compounds. The aim of this paper is to valorize the fruits that are not commercialized (e.g. due to inadequate size or physical damage) in infusions and decoctions. The antioxidant activity, the scavenging activity against reactive species, the phenolic profile and the intestinal effects of infusions and decoctions of dehydrated fruits were evaluated and compared. Decoctions presented the highest antioxidant activity and a good ability to capture $\mathrm{HOCl}$ and $\mathrm{NO}$. The phenolic composition of A. arguta present quinic acid, cis-caftaric acid and its derivatives, caffeoyl hexoside, luteolin glucuronide, quercetin derivatives and myristin, while $A$. deliciosa extracts were characterized by the presence of quinic acid, caffeic acid and its derivatives and caffeoyl hexoside. No adverse effects were observed on Caco-2 and HT29-MTX cells. Kiwiberry decoctions showed to be the best option to keep the fruits benefits.
\end{abstract}

\section{Introduction}

According to Food and Agriculture Organization of the United Nations (FAO), about one third of the world food production is wasted (Gustavsson, Cederberg, Sonesson, van Otterdijk, \& Meybeck, 2011). In Europe, the main cause for fruit and vegetables losses is due to the criteria implemented by the Regulation (EU) N. ${ }^{\circ} 543 / 2011$ that defines down standards for the minimum and maximum weight, colour and size (EC, 2011). These criteria allow for fresh products that are considered available for consumption. This is the particular case of kiwifruit and kiwiberry, which belongs to the genus Actinidia and are wild fruits extremely appreciated in Europe. The genus Actinidia (Actinidiaceae) is composed of $>50$ species, being A. deliciosa (commonly known as kiwifruit or kiwi) the greatest representative (Latocha, 2017). Kiwifruit is originated from Asia, but is worldwide appreciated mainly due to its flavour and nutritional benefits (Wojdyło, Nowicka, Oszmiański, \& Golis, 2017). In its turn, A. arguta, also known as baby kiwi or kiwiberry, is different from $A$. deliciosa due to its size (similar to a grape) and shape as well as colour, hairless skin, aroma and flavour (Wojdyło et al., 2017). Different varieties of kiwiberry are available on the market, but the most well-known are 'Ananasnaya', 'Geneva', 'Weiki', 'Issai', 'Jumbo', 'Ken's Red' and 'Maki'.

Kiwifruit is a fruit with great commercial importance, due to its nutritionally rich composition that classifies it as a health and wellbeing promoter (Ferguson \& Ferguson, 2003). Kiwifruit and kiwiberry are rich in phytochemicals, such as vitamins (mainly $\mathrm{C}$ ), organic acids, carotenoids ( $\beta$-carotene and lutein), minerals, sugars and phenolic acids (Ferguson \& Ferguson, 2003; Latocha, Krupa, Wołosiak, Worobiej, \& Wilczak, 2010; Latocha, Łata, \& Stasiak, 2015). For example, kiwifruit present about $60 \mathrm{mg} / 100 \mathrm{~g}$ fresh weight (fw) of ascorbic acid while in kiwiberry the vitamin C could reach $280 \mathrm{mg} / 100 \mathrm{~g} \mathrm{fw}$ (D'Evoli et al., 2015; Wojdyło et al., 2017). In addition, vitamin A, E and some B vitamins were also quantified (Latocha, 2017). The main sugars in both species were glucose, fructose and sucrose (D'Evoli et al., 2015; Nishiyama, Fukuda, Shimohashi, \& Oota, 2008; Wojdyło et al., 2017). The principal organic acids present are oxalic, citric, malic, quinic and 
succinic acids, being citric acid the predominant one (Nishiyama et al., 2008; Wojdyło et al., 2017). The levels of fatty acids have also an impact on the fruit acidity levels (Nishiyama et al., 2008). In what concerns to carotenoid composition, kiwifruit and kiwiberry are rich in lutein and $\beta$-carotene, presenting low concentrations of zeaxanthin, violaxanthin and $\alpha$-carotene (D'Evoli et al., 2015; Latocha et al., 2010; Latocha, 2017). In turn, high concentrations of chlorophyll $a$ and $b$ were detected (Latocha et al., 2010). The different species are similar in the fiber content (soluble and insoluble), representing about 3\% (D'Evoli et al., 2015; Latocha et al., 2010). In what concerns to minerals, kiwifruit is rich in potassium ( $\alpha 272 \mathrm{mg} / 100 \mathrm{~g} \mathrm{fw}$ ), also presenting other macro elements such as calcium $(\alpha 21 \mathrm{mg} / 100 \mathrm{~g} \mathrm{fw})$ and phosphor ( $\alpha$ $24.1 \mathrm{mg} / 100 \mathrm{~g} \mathrm{fw}$ ), while kiwiberry has high amounts of potassium and calcium (D'Evoli et al., 2015). The microelements (namely iron, zinc and manganese) have also been detected and quantified in both species (Ferguson \& Ferguson, 2003).

One of the major groups in Actinidia fruits composition are phenolic compounds. According to Wojdyło et al., kiwiberry is rich in flavonols, namely quercetin and kaempferol (Wojdyło et al., 2017). The principal quercetin derivatives were quercetin-3-O-rutinoside (ranging from 1.09 to $49.25 \mathrm{mg} / 100 \mathrm{~g}$ dry matter $(\mathrm{dm})$ for 'Jumbo' and 'Weiki', respectively) and quercetin-3-O-glucoside (ranging from 0.36 to $14.12 \mathrm{mg} /$ $100 \mathrm{~g} \mathrm{dm}$ for 'Jumbo' and 'Issai', respectively), while for kaempferol the dominant derivative was kaempferol-3-O-galactoside (between 2.25 and $39.36 \mathrm{mg} / 100 \mathrm{~g} \mathrm{dm}$ for 'Jumbo' and 'Bingo' varieties, respectively). In the same study, the authors quantified the phenolic acids, such as caffeic and chlorogenic acids, and 'Issai' variety presented the highest concentration of chlorogenic acid $(33.42 \mathrm{mg} / 100 \mathrm{~g} \mathrm{dm})$. The highest concentration of caffeic acid was determined in the 'Geneva' variety ( $4.09 \mathrm{mg} / 100 \mathrm{~g} \mathrm{dm})$ (Wojdyło et al., 2017). The 'Ananasnaya' and 'Issai' varieties are characterized by a larger constitution in procyanidins (condensed tannins), which explains the slight astringency and bitterness of the kiwiberry (Leontowicz et al., 2016).

Kim et al. determined in $2.66 \mathrm{~g} / 100 \mathrm{fw}$ and $0.18 \mathrm{~g} / 100 \mathrm{fw}$, respectively, the average amount of the total phenolic content in the skin and flesh of kiwifruit (Kim, Beppu, \& Kataoka, 2009). According to the authors, the skin phenolic content is 15 times higher than the flesh. Kiwifruits are rich in flavanols, the predominant phenolic sub-class, with epicatechin $(119.38-171.79 \mu \mathrm{g} / \mathrm{g} \mathrm{dm})$ and catechin $(38.07-73.28 \mu \mathrm{g} / \mathrm{g} \mathrm{dm})$ being the main monomeric phenolics in the flesh extracts (Jiao, Kilmartin, Fan, \& Quek, 2018). Rutin $(50.56-69.16 \mu \mathrm{g} / \mathrm{g} \mathrm{dm})$ and vanillic acid $(43.48-65.30 \mu \mathrm{g} / \mathrm{g} \mathrm{dm})$ are also present in relatively high amounts in flesh samples (Jiao et al., 2018). Guo et al. reported twenty-one phenolic compounds in kiwifruit juices that mainly belong to flavonols, flavan-3-ols, hydroxycinnamic and hydroxybenzoic acids classes (Guo, Yuan, Dou, \& Yue, 2017).

In addition to this nutritional and bioactive composition, several biological activities have been associated to these fruits, namely antioxidant, antidiabetic and anticancer activities, highlighting their potential as functional foods (Wojdyło et al., 2017; Zuo, Wang, Fan, Tian, \& Liu, 2012). In this way, the consumption form of these fruits show their versatility and potential, being consumed fresh or processed in alcoholic beverages, juices, ice cream or jams. However, it is noticed that there is still a great challenge of commercialization and valorisation of these fruits, particularly those that are not conform to be commercialized due to inadequate size, improper ripeness or physical damage, being considered as waste. Based on the health-related potential properties of herbal infusions and decoctions, the main goal of this study is to provide new information about the bioactivity of dehydrated fruits of A. arguta vs. A. deliciosa infusions and decoctions. To the best of our knowledge this is the first study that develop and characterize infusion of kiwifruit and kiwiberry. To achieve this aim, the content of phenolic compounds was accessed by HPLC-DAD-MS. The in vitro antioxidant capacity was determined by DPPH and FRAP methodologies and the radical scavenging capacity was assessed on different oxygen and nitrogen species. Finally, the effect of decoctions and infusions on intestinal cells (Caco-2 and HT29-MTX) was also evaluated.

\section{Materials and methods}

\subsection{Samples}

A. arguta fruits ('Jumbo' cultivar) were collected during September 2017 in a kiwiberry orchard (Mini-Kiwi Farm) located in Landim, Vila Nova de Famalicão, Portugal (GPS: 41.376830,-8.469748). A. deliciosa fruits ('Hayward' cultivar) were of biological origin and obtained in November 2017 in a traditional market of Oporto, Portugal. Both fruit species with peel and in a mature stage were dehydrated (Lacor, Spain) during $48 \mathrm{~h}$, crushed (Flama, Portugal), fully homogenized and stored at $4{ }^{\circ} \mathrm{C}$ until infusions and decoctions preparation.

\subsection{Decoctions and infusions' extracts preparation}

To prepare decoctions, $2 \mathrm{~g}$ of each fruit were added to $100 \mathrm{~mL}$ of distilled water and heated till boiling in a stainless steel pot. After, the mixture was left at boiling temperature for $5 \mathrm{~min}$ and filtered through Whatman No. 1 filter paper. For the infusions, $2 \mathrm{~g}$ were added to $100 \mathrm{~mL}$ of boiling distilled water in a stainless steel pot and left for $5 \mathrm{~min}$, being then filtered through Whatman No. 1 filter paper.

Decoctions and infusions of $A$. arguta and A. deliciosa were prepared. In the case of total phenolic and flavonoid content (TPC and TFC, respectively) as well as the antioxidant activity (through the inhibition of the 1,1-diphenyl-2-picrylhydrazyl radical (DPPH') and the antioxidant power by ferric ion reduction (FRAP) the solutions were directly used after preparation. For the remaining assays, after being filtered, the solutions were frozen at $-80^{\circ} \mathrm{C}$ for subsequent lyophilisation (Telstar, model Cryodos -80, Spain). After lyophilisation the samples were stored at $4{ }^{\circ} \mathrm{C}$ until analysis.

\subsection{Analysis of infusions and decoctions physical properties}

\subsubsection{Color}

A colorimeter CR-400 (Konica Minolta, Tokyo, Japan) was used to evaluate color, being the results expressed in the color space CIE 1976 $\mathrm{L} * \mathrm{a} * \mathrm{~b} *$. According to La Commission Internationale de l'Éclairage (CIE), $L^{*}$ coordinate represents lightness, $a^{*}$ the position between red and green and $b^{*}$ the position between yellow and blue. The system was calibrated using a white tile.

\subsection{2. $\mathrm{pH}$}

The $\mathrm{pH}$ was analyzed with a $\mathrm{pH}$ meter (691, Mettler, Greifensee, Switzerland) equipped with a glass electrode. The measurements were performed in triplicate for each sample.

\subsection{Analysis of infusions and decoctions chemical properties}

\subsubsection{Total phenolic content (TPC) of infusions and decoctions}

TPC was determined spectrophotometrically according to the FolinCiocalteu procedure (Singleton \& Rossi, 1965), with minor modifications (Alves et al., 2010). The TPC of the extracts was expressed as $\mathrm{mg}$ of gallic acid equivalents (GAE) per litter (mg GAE/L).

\subsubsection{Determination of total flavonoids content (TFC)}

Total flavonoid content (TFC) was determined according to Rodrigues et al. (2013). The TFC was expressed as milligrams of catechin equivalents per litter (mg CAE/L).

\subsubsection{In vitro antioxidant activity}

$\mathrm{DPPH}^{\circ}$ radical-scavenging activity and ferric reducing antioxidant power (FRAP) assays were employed to evaluate the antioxidant activity. 
2.4.3.1. DPPH free radical scavenging assay. This assay was performed according to Barros et al. (Barros, Baptista, \& Ferreira, 2007), with minor modifications (Marangi et al., 2018). Results where expressed as $\mathrm{DPPH}^{*}$ scavenging activity (DPPH $\left.{ }^{*} \mathrm{SA}\right)$.

2.4.3.2. Ferric reducing antioxidant power (FRAP) assay. Ferric reducing or antioxidant power was determined according to Benzie and Strain (1999), with minor modifications (Marangi et al., 2018), being the results expressed in $\mu \mathrm{M}$ ferrous sulphate equivalents per litter ( $\mu \mathrm{M}$ FSE/ L).

\subsection{Reactive species scavenging capacity}

A Synergy HT Microplate Reader (BioTek Instruments, Inc., Winooski, VT, USA) was employed to evaluate the reactive species scavenging capacity. This plate was equipped with a thermostat and capable to measurer chemiluminescence, fluorescence and UV/Vis. Standards and samples were prepared according to Marangi et al. (2018) and the same positive controls were used. The $\mathrm{IC}_{50}$ values (the concentration required to obtain an inhibition capacity of 50\%) were obtained from the curves of percentage of inhibition versus extract concentration.

\subsubsection{Superoxide radical scavenging assay}

The superoxide anion radical $\left(\mathrm{O}_{2}{ }^{-}\right)$assay was performed according to Gomes et al. (2007).

\subsubsection{Hydrogen peroxide scavenging assay}

The hydrogen peroxide $\left(\mathrm{H}_{2} \mathrm{O}_{2}\right)$ scavenging assay was also performed according to Gomes et al. (2007).

\subsubsection{Hypochlorous acid scavenging assay}

The hypochlorous acid ( $\mathrm{HOCl}$ ) assay was based on a fluorescent methodology (Gomes et al., 2007).

\subsubsection{Nitric oxide scavenging assay}

The nitric oxide ( $\mathrm{NO}$ ) scavenging assay used as positive control quercetin, expressing the results as the inhibition (in percentage) of NOinduced oxidation of DAF-2, according to Gomes et al. (2007).

\subsubsection{Peroxyl radical scavenging assay}

The peroxyl radical (ROO') assay was performed according to Ou, Hampsch-Woodill, and Prior (2001) based on the monitoring effect of the tested extracts on the fluorescence decay resulting from ROO-induced oxidation of fluorescein. The standard control used was Trolox and the results were expressed as ROO-induced oxidation of fluorescein.

2.5.6. Determination of the scavenging activity of the peroxynitrite $\left(\mathrm{ONOO}^{-}\right)$in absence of $\mathrm{NaHCO}_{3}$

The scavenging capacity of peroxynitrite $\left(\mathrm{ONOO}^{-}\right)$in the absence of sodium bicarbonate employed acid and quercetin as positive controls, expressing the results as the inhibition, in percentage, of $\mathrm{ONOO}^{-}$induced oxidation of DHR, according to de Francisco et al. (2018).

2.5.7. Determination of the scavenging activity of the peroxynitrite $\left(\mathrm{ONOO}^{-}\right)$in presence of $\mathrm{NaHCO}_{3}$

The scavenging capacity of peroxynitrite $\left(\mathrm{ONOO}^{-}\right)$in the presence of sodium bicarbonate was performed according to de Francisco et al. (2018) using the percentage inhibition of $\mathrm{ONOO}^{-}$-induced oxidation of DHR to express the results.

\subsection{Vitamin $C$ determination}

\subsubsection{Samples preparation}

For the determination of vitamin $\mathrm{C}$ content (L-ascorbic acid and dehydroascorbic acid), samples were prepared according to Valente, Albuquerque, Sanches-Silva, and Costa (2011) and Albuquerque et al. (2016). All stages of analyses were performed under controlled temperature $\left(20^{\circ} \mathrm{C}\right)$ and protected from light.

\subsubsection{HPLC-DAD analysis}

Quantitative determination of L-ascorbic acid was carried out using a previously validated method by Valente et al. (2011). Dehydroascorbic acid was determined indirectly, by difference of total vitamin C (obtained after dehydroascorbic acid reduction) and the L-ascorbic acid content of the sample. Analysis were performed on an Alliance 2695 HPLC system (Waters, Milford, MA, USA), equipped with a Waters 2996 photodiode array detector, using a SynergiTM Hydro-RP $(150 \mathrm{~mm} \times 4.6 \mathrm{~mm}$ I.D., $4.0 \mu \mathrm{m}$ particle size) analytical column protected with a SecurityGuard Cartridge AQ C18 (40 $\mathrm{mm} \times 2.0 \mathrm{~mm}$ I.D., $5 \mu \mathrm{m}$ particle size) from Phenomenex (Torrance, California, USA). Column temperature was kept at $30^{\circ} \mathrm{C}$ and the autosampler at $4{ }^{\circ} \mathrm{C}$. A flow rate of $0.6 \mathrm{~mL} / \mathrm{min}$ was used with an injection volume of $20 \mu \mathrm{L}$. The total run time of analysis was $10 \mathrm{~min}$. Samples were scanned between 200 and $400 \mathrm{~nm}$ and monitored at a wavelength of $245 \mathrm{~nm}$. Identification of $\mathrm{L}$-ascorbic acid was performed by comparing retention times and absorption spectra of the peaks with reference standards. The peak areas were quantified and processed with EmpowerTM version 2.0 software (Waters, Milford, MA, USA). The results were expressed in $\mathrm{mg} / 100 \mathrm{~g}$ of dry sample.

\subsection{Infusions and decoctions phytochemical characterization}

\subsubsection{Mucilage separation}

The clean-up of mucilage was carried out according to Henriques et al. (2017), with slight modifications. The extract were weighed and water was added to extract dissolution. Afterwards, ethanol (96\%) was added and the solution cooled during $15 \mathrm{~h}$ and centrifuged for $30 \mathrm{~min}$ at $4{ }^{\circ} \mathrm{C}$ with $4500 \mathrm{~g}$. The pellet was removed and the ethanol fraction in the supernatant was evaporated. Samples were then freeze-dried, reconstituted with Milli-Q water and injected on HPLC-DAD-MS.

\subsubsection{LC-DAD/ESI-MS analysis}

Samples were analyzed using the same methodology described by Fernandes et al. (2009). The \% area of tentatively identified compounds was determined at $280 \mathrm{~nm}$.

\subsection{Cells assays}

\subsubsection{Cell lines, primary cell isolation and culture conditions}

Caco-2 clone type C2BBe1 cells were obtained from American Type Culture Collection (ATCC, USA) and HT29-MTX cell line was kindly provided by Dr. T. Lesuffleur (INSERMU178, Villejuif, France). Passage 76-78 of Caco-2 clone type C2BBe1 and passage 34-37 of HT29-MTX were used for the MTT assay. Cells were grown according to the methodology described by de Francisco et al. (2018).

\subsubsection{MTT assay}

The MTT assay was performed according to the procedure described by de Francisco et al. (2018), being the cells incubated with $0.1-1.0 \mathrm{mg} / \mathrm{mL}$ of infusions and decoctions for $24 \mathrm{~h}$ at $37^{\circ} \mathrm{C}$. DMEM was used as positive control, while Triton X-100 1\% (w/v) was the negative control.

\subsubsection{LDH assay}

LDH assay was performed according to Rodrigues et al. (2013).

\subsection{Statistical analysis}

SPSS 24.0 software (SPSS Inc., Chicago, IL, USA) was used for the statistical analysis, being all data reported as mean \pm standard 
Table 1

Physical characteristics ( $\mathrm{pH}$ and color parameters) of $A$. arguta and A. deliciosa infusions and decoctions ( $n=3$ ).

\begin{tabular}{|c|c|c|c|c|c|}
\hline \multirow{2}{*}{\multicolumn{2}{|c|}{ Physical Parameter }} & \multicolumn{4}{|l|}{ Sample } \\
\hline & & A. arguta decoction & A. arguta infusion & A. deliciosa decoction & A. deliciosa infusion \\
\hline \multirow[t]{3}{*}{ Color } & $L^{*}$ & $25.377 \pm 0.005$ & $24.983 \pm 0.017$ & $26.103 \pm 0.029$ & $25.397 \pm 0.048$ \\
\hline & $a^{*}$ & $-2.213 \pm 0.012$ & $-2.283 \pm 0.024$ & $-2.457 \pm 0.058$ & $-2.357 \pm 0.054$ \\
\hline & $b^{*}$ & $3.353 \pm 0.021$ & $3.810 \pm 0.029$ & $2.940 \pm 0.014$ & $3.300 \pm 0.029$ \\
\hline $\mathrm{pH}$ & & $3.76 \pm 0.01$ & $3.81 \pm 0.02$ & $3.70 \pm 0.01$ & $3.70 \pm 0.01$ \\
\hline
\end{tabular}

deviation of three. The normal distribution and the homogeneity of variances were, respectively, accessed by Shapiro-Wilk's and Levene's tests. For all assays, the data were normal and the homogeneity of variances confirmed. To evaluate the differences between samples the one way ANOVA was used. Tukey's HSD test was employed for the post hoc comparisons of the means, being $\mathrm{p}<0.05$ accepted as denoting significance. A correlation study was performed and Pearson's regression coefficient ' $r$ ' with P-value was selected. A 95\% confidence interval for the correlation coefficient was chosen. GraphPad Prism 5 software (GraphPad, La Jolla, CA, USA) was employed to calculate the $\mathrm{IC}_{50}$ values of Reactive Oxygen Species (ROS) and Reactive Nitrogen Species (RNS) scavenging activity.

\section{Results and discussion}

\subsection{Physical characterization of infusions and decoctions}

The color assessment is a complementary methodology usually employed to evaluate the products consumer acceptance. Table 1 summarizes the physical properties of infusions and decoctions of $A$. arguta and $A$. deliciosa. The three coordinates represent the color luminosity $\left(\mathrm{L}^{*}\right)$, the position between red and green $\left(\mathrm{a}^{*}\right)$ and the position between yellow and blue ( $\left.b^{*}\right)$.

Regarding the $\mathrm{L}^{*}$ parameter, decoctions and infusions of both species showed low luminosity, with values ranging from 24.983 to 26.103 for $A$. arguta infusion and A. deliciosa decoction, respectively. For both species, negative values were observed for the a* parameter, which is associated with greenish coloration, with results ranging between -2.213 for $A$. arguta decoction and -2.457 for the A. deliciosa decoction. A tendency for the yellow was observed with the $b^{*}$ parameter, being the results positive for all samples.

In what concerns to $\mathrm{pH}$ (Table 1 ), the results were similar for all samples, presenting an acidic value. Nevertheless, the values obtained for $A$. arguta were slightly higher, without significant differences between samples ( $\mathrm{p}>0.05)$. The A. arguta decoction presented a $\mathrm{pH}$ value of 3.76 and the infusion of 3.81 , while for A. deliciosa both results were 3.70 .

Reddy et al. analysed the $\mathrm{pH}$ of the most consumed beverages in the United States of America (USA) (Reddy, Norris, Momeni, Waldo, \& Ruby, 2016). According to the authors, almost beverages had acidic $\mathrm{pH}$. The lemon juice, for example, presented a pH of 2.25, the orange had a value of 3.82 or another sample 2.82, the Coke obtained the result of 2.37 and the $7_{\mathrm{UP}}$ and the lime tea from Nestea had a $\mathrm{pH}$ of 3.24 and 2.94, respectively (Reddy et al., 2016). The infusions and the decoctions developed in this study have a similar acidity to the beverages analysed by Reddy et al. Further studies are needed to conclude about the consumer's acceptance,

\subsection{Bioactive composition of infusions and decoctions}

Polyphenols are a vast group of compounds that over the last few years become extremely important to the diet. Several characteristics have been associated with these compounds, such as colour, bitter, astringency or antioxidant activity. Table 2 summarizes the TPC, TFC and antioxidant activity of $A$. arguta and $A$. deliciosa infusions and decoctions.

According to Table 2, the TPC ranged between 60.50 and $146.35 \mathrm{mg}$ GAE/L, with the highest value corresponding to A. arguta decoction and the lowest to $A$. deliciosa infusion $(p<0.05)$. The $A$. arguta samples presented the highest TPC. Significant differences $(p<0.05)$ were observed between species as well as between infusions and decoctions of each species. This may be due to the contact time and the temperature at which the decoctions are prepared, allowing a greater and better extraction of the phenolic compounds.

Due to the importance of infusions and decoctions to the human diet, as well as their acceptance by consumers, this issue has been studied by several authors. For example, Pereira et al. characterized the phenolic groups of infusions and decoctions of different parts of Crithmum maritimum (Pereira et al., 2017). Regarding TPC, the values obtained for decoctions were always higher than infusions, although no significant differences were observed. The TPC ranged from 62 to $176.5 \mathrm{mg} \mathrm{GAE} / \mathrm{L}$, with leaf decoction showing the highest TPC. These values are similar to the one reported in Table 2. Šavikin et al. evaluated the phenolic content of decoctions and infusions of different red fruits, namely Aronia melanocarpa, Ribes nigrum and Vaccinium myrtillus, reporting values between 601 and $888 \mathrm{mg} \mathrm{GAE} / \mathrm{L}$ (Šavikin et al., 2014). The highest content was found for A. melanocarpa, followed by $V$. myrtillus and $R$. nigrum. Significant differences $(p<0.05)$ were observed between infusions of $A$. melanocarpa and $V$. myrtillus. According to the authors, the continuous temperature of the decoctions leads to a lower TPC when compared to the infusions. However, these samples were firstly extracted with ethanol $(70 \%)$ in ultrasonic water, which can influence the results obtained and lead to higher values when compared to those presented in Table 2.

In what concerns to TFC, the results ranged from 7.84 to $32.29 \mathrm{mg}$ CAE/L, namely for the $A$. deliciosa infusion and A. arguta decoction. Once again, the values obtained clearly demonstrated that the $A$. arguta decoction has a higher flavonoid content. It was also noted that the $A$. arguta decoction and the infusion presented higher values when compared to A. deliciosa samples. Statistical analysis $(p<0.05)$ showed that there were significant differences between all samples, as well as decoction and infusion of each species. This fact, as previously observed for the TPC, may be due to the contact time and the temperature at which the fruit is submitted in the decoction, which causes a greater extraction. Pereira et al. also analysed the TFC in different extracts of $C$. maritimum, using rutin as the standard solution (RE) (Pereira et al., 2017). The lowest TFC was reported for stem infusion (114.5 mg RE/L) and the highest content for the leaf decoction (289 mg RE/L). Decoctions presented the highest values, exception made for flowers whose TFC in the infusion was higher. Thus, although the values found by these authors are about ten times higher than the ones reported in the present study, it can be observed that decoctions presented the highest TFC.

Currently, antioxidant activity is one of the most valuable parameters. In addition, there is a growing demand for natural antioxidants, focusing the research on the determination of the antioxidant activity of plants and fruits extracts. Decoctions and infusions are included in this group. The antioxidant capacity based on inhibition of the $\mathrm{DPPH}^{-}$radical by infusions and decoctions was expressed as percent inhibition at the highest tested concentration $(20 \mathrm{~g} / \mathrm{L})$. The results shown that the 
Table 2

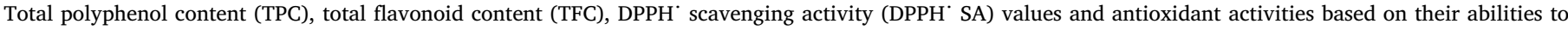

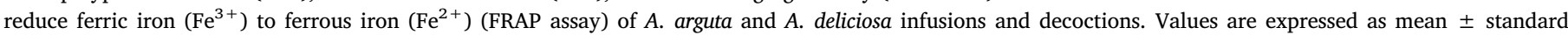

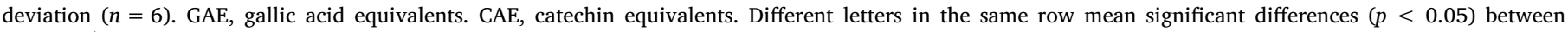
samples. "In the same sample indicate significant differences between infusion and decoction $(p<0.05)$ according to Tukey's HSD test.

\begin{tabular}{|c|c|c|c|c|c|}
\hline Sample & & $\begin{array}{l}\text { TPC } \\
(\mathrm{mg} \mathrm{GAE} / \mathrm{L})\end{array}$ & $\begin{array}{l}\text { TFC } \\
(\mathrm{mg} \mathrm{CAE} / \mathrm{L})\end{array}$ & $\begin{array}{l}\text { FRAP } \\
(\mu \mathrm{mol} \mathrm{FSE} / \mathrm{L})\end{array}$ & $\begin{array}{l}\mathrm{DPPH}^{\cdot} \mathrm{SA} \\
(\%)\end{array}$ \\
\hline \multirow[t]{2}{*}{ A. arguta } & Decoction & $146 \pm 3.10^{\mathrm{a}, *}$ & $32.4 \pm 1.29^{\mathrm{a}, *}$ & $1292 \pm 20.9^{\mathrm{a}, *}$ & $56.7 \pm 8.52^{\mathrm{a}}$ \\
\hline & Infusion & $93.8 \pm 2.21^{\mathrm{b}}$ & $17.8 \pm 1.44^{\mathrm{b}}$ & $801 \pm 8.21^{\mathrm{c}}$ & $42.9 \pm 2.62^{\mathrm{a}, \mathrm{b}}$ \\
\hline \multirow[t]{2}{*}{ A. deliciosa } & Decoction & $77.1 \pm 2.11^{\mathrm{c}, *}$ & $9.89 \pm 0.64^{\mathrm{c}, *}$ & $849 \pm 17.5^{\mathrm{b}}$ & $37.2 \pm 1.06^{\mathrm{b}}$ \\
\hline & Infusion & $60.5 \pm 1.37^{\mathrm{d}}$ & $7.84 \pm 0.75^{\mathrm{d}}$ & $871 \pm 44.6^{b}$ & $54.3 \pm 7.62^{\mathrm{a}}$ \\
\hline
\end{tabular}

Table 3

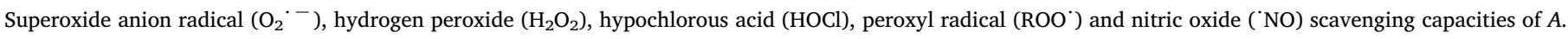
arguta and $A$. deliciosa infusions and decoctions. Values are expressed as mean \pm standard deviation $(n=3)$.

\begin{tabular}{|c|c|c|c|c|c|}
\hline \multirow[t]{3}{*}{ Reactive species } & \multicolumn{5}{|l|}{$\mathrm{IC}_{50}(\mu \mathrm{g} / \mathrm{mL})$} \\
\hline & \multicolumn{4}{|l|}{ ROS } & \multirow{2}{*}{$\begin{array}{l}\text { RNS } \\
\mathrm{NO}^{\circ}\end{array}$} \\
\hline & $\mathrm{O}_{2} \cdot-$ & $\mathrm{H}_{2} \mathrm{O}_{2}$ & $\mathrm{HOCl}$ & $\mathrm{ROO}^{\circ}\left(\mathrm{m}_{\text {amostra }} / \mathrm{m}_{\text {Trolox }}\right)$ & \\
\hline \multicolumn{6}{|l|}{ A. arguta } \\
\hline Decoction & NA & NA & $15.50 \pm 3.02$ & $0.0087 \pm 0.0005$ & $27.83 \pm 2.54$ \\
\hline Infusion & NA & NA & $27.49 \pm 1.81$ & $0.0121 \pm 0.0003$ & $36.03 \pm 2.36$ \\
\hline \multicolumn{6}{|l|}{ A. deliciosa } \\
\hline Decoction & NA & NA & $15.67 \pm 2.39$ & $0.0114 \pm 0.0004$ & $27.51 \pm 2.34$ \\
\hline Infusion & NA & NA & $47.76 \pm 2.42$ & $0.0103 \pm 0.0006$ & $18.96 \pm 1.96$ \\
\hline \multicolumn{6}{|l|}{ Positive controls } \\
\hline Ascorbic acid & $370.10 \pm 27.98$ & $93.84 \pm 4.59$ & $2.23 \pm 0.05$ & $0.8171 \pm 0.44$ & - \\
\hline Quercetin & - & - & $0.21 \pm 0.01$ & $5.0540 \pm 0.44$ & $0.06 \pm 0.01$ \\
\hline
\end{tabular}

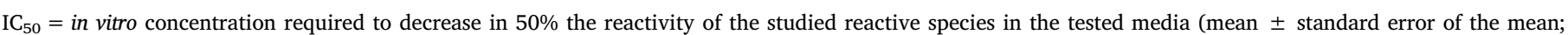
$n=3) .{ }^{\mathrm{NA}}$ No activity was determined up to the highest tested concentration $(1 \mathrm{mg} / \mathrm{mL})$.

percent inhibition ranged from 37.19 to $56.65 \%$, with the highest value being obtained for $A$. arguta decoction. The statistical analysis $(p<0.05)$ revealed that significant differences were observed between decoctions of the different species. In addition, infusion of $A$. arguta did not shown significant differences $(p>0.05)$ neither for the decoction of the same species nor for $A$. deliciosa infusion and decoction. On the other hand, the $A$. deliciosa decoction showed significant differences $(p<0.05)$ for the infusion of the same species and for the $A$ arguta decoction. Thus, the highest antioxidant activity quantified by the DPPH assay was obtained for A. arguta decoction, while for A. deliciosa the infusion process lead to the best result. In order to determine the antioxidant activity, Pereira et al. submitted the different extracts of $C$. maritimum to the DPPH radical scavenging assay (Pereira et al., 2017). An inhibition percentage between 79.4 and $88.0 \%$ per cup of tea was reported, with the lowest result being described for stems infusion and the highest for the $C$. maritimum flowers infusion.

The ability of extracts to reduce ferric ions was determined using the FRAP assay. According to Table 2, the increasing order of the antioxidant activity was $A$. arguta infusion $<A$. deliciosa decoction $<A$. deliciosa infusion $<A$. arguta decoction. As expected, the $A$. arguta decoction presented the highest value for the reduction of the ferric ion (1292.45 $\mu \mathrm{mol} \mathrm{FSE/L)} \mathrm{and} \mathrm{the} \mathrm{lowest} \mathrm{result} \mathrm{was} \mathrm{obtained} \mathrm{for} \mathrm{the} \mathrm{infu-}$ sion of the same species $(801.53 \mu \mathrm{mol} F \mathrm{FE} / \mathrm{L})$. Statistical differences $(p<0.05)$ were observed between $A$. arguta infusion and decoction. On the contrary, no statistical differences $(p>0.05)$ were reported between $A$. deliciosa extracts. Lv et al. analysed the antioxidant activity of different varieties of Chinese black tea obtained by infusion (Lv, Zhang, Shi, \& Lin, 2017). The Fuzhuan and Liubao teas had a similar ferric ion reduction capacity, obtaining values of $184.31 \mu \mathrm{mol} / \mathrm{L}$ and $188.46 \mu \mathrm{mol} / \mathrm{L}$, respectively, while Pu-erh tea had a lower capacity $(127.35 \mu \mathrm{mol} / \mathrm{L})$. In this way, the results obtained for $A$. arguta and $A$. deliciosa infusions and decoctions were higher than black tea, presenting a greater antioxidant activity.
The possible correlation between the antioxidant activity (based on the $\mathrm{DPPH}^{-}$radical scavenging capacity and the FRAP assay) and the TPC and TFC results was assessed by Pearson correlation. A strong positive correlation $(r=0.9865 ; p<0.05)$ was observed between TPC/TFC as well as between FRAP and TPC $(r=0.8654 ; p<0.05)$ or TFC $(r=0.8549 ; p<0.05)$. Nevertheless, a moderate correlation $(r=0.5250 ; p<0.05)$ was observed between DPPH ${ }^{\circ}$ and FRAP. Finally, there was a weak correlation between $\mathrm{DPPH}^{\circ}$ and TPC $(r=0.3304 ; p<0.05)$ as well as between $\mathrm{DPPH}^{-}$and TFC $(r=0.1753 ; p<0.05)$.

\subsection{ROS and RNS scavenging assays}

Nowadays, consumers have an increasing concern with health and well-being, demonstrating a huge interest on foods and beverages with bioactive and functional compounds. The production of reactive species occurs naturally in physiological processes, such as in the defence against infectious agents or in cell signalling (Almeida et al., 2018). An imbalance between the production of pro-oxidant reactive species and the cells antioxidant defence capacity leads to a phenomenon called oxidative stress that can damage the major cellular constituents, namely lipids, proteins and DNA. In this sense, free radicals can cause oxidation and damage to biological molecules. However, phenolic compounds are able to neutralize these harmful actions due to their antioxidant activity. The results of the ROS and RNS scavenging capacity are summarized in Table 3.

According to the obtained results, $A$. arguta and $A$. deliciosa infusions and decoctions were able to capture reactive species (with the exception of $\mathrm{O}_{2}{ }^{-}$and $\mathrm{H}_{2} \mathrm{O}_{2}$ ) presenting lower $\mathrm{IC}_{50}$ values.

The superoxide anion radical plays an important role in the redox cellular signalling and in the development of pathophysiological conditions, such as hypertension, inflammation or atherosclerosis (Pistón et al., 2014). A. arguta decoction presented the highest inhibition 
percentage (49.18\%), followed by A. deliciosa decoction (43.96\%), A. arguta infusion (35.82\%) and $A$. deliciosa infusion (29.88\%), not being possible to determine the $\mathrm{IC}_{50}$ at the highest concentration tested $(1000 \mu \mathrm{g} / \mathrm{mL})$.

$\mathrm{H}_{2} \mathrm{O}_{2}$ is the less reactive species among ROS (de Francisco et al., 2018). However, this species can produce other species with toxic effects, such as the hydroxyl radical (HO'). As can be observed in Table 3, it was not possible to determine the $\mathrm{IC}_{50}$ for the highest concentration tested $(1000 \mu \mathrm{g} / \mathrm{mL})$. At this concentration, the highest scavenging activity was observed with $A$. deliciosa infusion (49.56\%), while for A. arguta the highest inhibition was obtained with the decoction (44.35\%).

$\mathrm{HOCl}$ is another oxygen species involved in several pathologies induced by chronic inflammation. According to Table 3, decoctions had a good ability to uptake the $\mathrm{HOCl}$, presenting low $\mathrm{IC}_{50}$ values, respectively, $15.50 \mu \mathrm{g} / \mathrm{mL}$ and $15.67 \mu \mathrm{g} / \mathrm{mL}$ for $A$. arguta and $A$. deliciosa decoctions. On the other hand, the infusions shown high $\mathrm{IC}_{50}$ values, namely $27.49 \mu \mathrm{g} / \mathrm{mL}$ for $A$. arguta and $47.76 \mu \mathrm{g} / \mathrm{mL}$ for $A$. deliciosa. It is also noticeable that the $A$. arguta species has a greater ability to capture $\mathrm{HOCl}$ when compared to A. deliciosa.

The ORAC assay is a rapid method to determine the uptake capacity of ROO ' radical. The A. arguta infusion is the most efficient according to the obtained results, while its decoction is the less effective presenting ratios of, respectively, 0.0121 and 0.0087 . Regarding A. deliciosa, the decoction showed a higher uptake capacity $(0.0114)$ when compared to the infusion (0.0103).

For the RNS assay, only NO uptake capacity was evaluated (Table 3 ). The reactive capacity of nitrogen species are associated with deleterious effects on the activity of numerous biological molecules. The production of RNS is initiated by the NO production, induced by nitric oxide synthetase through the conversion of L-arginine to L-citrulline (Pacher, Beckman, \& Liaudet, 2007). This reactive species is responsible for several diseases, particularly atherosclerosis, diabetes, cancer, asthma, cardiovascular and neurodegenerative diseases, such as Alzheimer's and Parkinson's (Pacher et al., 2007; Pistón et al., 2014). As shown in Table 3, A. deliciosa had the best result ( IC $_{50}=18.96 \mu \mathrm{g} / \mathrm{mL}$ ). It was also notorious that the A. deliciosa, compared to A. arguta, is more effective.

Piston et al. evaluated different extracts of artichoke leaves (namely infusion, decoction and hydroalcoholic extract) regarding ROS and RNS scavenging activity (Pistón et al., 2014). Concerning the inhibition of $\mathrm{O}_{2}{ }^{--}$, the lowest $\mathrm{IC}_{50}$ was obtained for the infusion with $34 \mu \mathrm{g} / \mathrm{mL}$. As in the present study, Pistón et al. did not find activity against $\mathrm{H}_{2} \mathrm{O}_{2}$. The evaluation of the $\mathrm{HOCl}$ uptake revealed good results for the three extracts, with the most efficient being the infusion $\left(\mathrm{IC}_{50}=3.7 \mu \mathrm{g} / \mathrm{mL}\right.$ ). The ORAC assay also revealed that the infusion was more efficient. The values reported for ${ }^{\circ} \mathrm{NO}$ uptake ranged between 5.5 and $11.0 \mu \mathrm{g} / \mathrm{mL}$ for infusion and hydroalcoholic extract, respectively, being lower than those found in the present study.

Almeida et al. described the ROS and RNS scavenging activity of $A$. arguta leaves, reporting a greater capacity to capture $\mathrm{O}_{2}{ }^{-}-\mathrm{H}_{2} \mathrm{O}_{2}$ and NO (Almeida et al., 2018). On the contrary, the capacity to scavenge $\mathrm{HOCl}$ species was more efficient for $A$. arguta and A. deliciosa infusions and decoctions, since the $A$. arguta leaves presented $\mathrm{IC}_{50}$ values ranging between 82.33 and $137.50 \mu \mathrm{g} / \mathrm{mL}$ for the aqueous and hydroalcoholic extract, respectively (Almeida et al., 2018). As for the ORAC assay, Almeida et al. were unable to determine the $\mathrm{IC}_{50}$ value at the maximum concentration tested $(1000 \mu \mathrm{g} / \mathrm{mL})$ (Almeida et al., 2018). The results were also in line with Marangi et al. using a Multi-Frequency Multimode Modulated Technology to extract kiwiberry leaves (Marangi et al., 2018).

\subsection{Vitamin $C$ concentration}

Vitamin C, particularly present in fruits and vegetables, is one of the most important water-soluble vitamins, being widely used as a food additive and antioxidant (Pénicaud, Peyron, Bohuon, Gontard, \&
Guillard, 2010; Valente et al., 2011). L-ascorbic acid is the active biological form, being an effective antioxidant due to its high electron donation power and rapid conversion in the active reduced form. Thus, the determination of the amount of vitamin $\mathrm{C}$ is particularly important to understand the impact of diet on human health (Valente et al., 2011). According to Albuquerque et al. (2016) and Spinola, Mendes, Camara, and Castilho (2012), it is extremely complex the simultaneous detection of L-ascorbic acid and dehydroascorbic acid due to the low absorption of dehydroascorbic acid in the ultraviolet zone. In that way, the authors suggest an indirect determination by difference with the total vitamin C (obtained after the reduction of the dehydroascorbic acid) and the Lascorbic acid content of the sample (Albuquerque et al., 2016).

Unfortunately, it was not possible to determine the total vitamin $\mathrm{C}$ and the L-ascorbic acid content for A. arguta decoction and infusion, probably due to the limit of detection (LOD) of the method employed $(0.035 \mu \mathrm{g} / \mathrm{mL})$. For A. deliciosa, the infusion revealed a higher total vitamin $C$ content $(770.5 \pm 1.55 \mathrm{mg} / 100 \mathrm{~g})$ when compared to the decoction $(422.5 \pm 3.20 \mathrm{mg} / 100 \mathrm{~g})$. The L-ascorbic acid content is also higher in the infusion $(485.5 \pm 2.91 \mathrm{mg} / 100 \mathrm{~g}$ versus $149.4 \pm 0.18 \mathrm{mg} / 100 \mathrm{~g}$ for the decoction). Regarding the dehydroascorbic acid, the $A$. deliciosa decoction and infusion presented results of, respectively, $273.0 \pm 3.30 \mathrm{mg} / 100 \mathrm{~g}$ and $285.0 \pm 4.38 \mathrm{mg} /$ $100 \mathrm{~g}$.

It is well known that vitamin $\mathrm{C}$ is a thermolabile compound, being also unstable under the presence of oxygen, light and heavy ions, as well as with increased water activity (Latocha, 2017; Mditshwa, Magwaza, Tesfay, \& Opara, 2017). This behaviour can be observed in the results obtained for decoctions, since the contact time and the temperature is considerably higher. Nevertheless, it was not possible to obtain results for A. arguta extracts, which is not expected since it is described that the vitamin $\mathrm{C}$ values in this fruit are higher than the ones reported for A. deliciosa (Latocha, 2017). According to Wojdyło et al., the vitamin $C$ content in $A$. arguta fruits are comprised between 76.09 and $282.56 \mathrm{mg} / 100 \mathrm{~g} \mathrm{fw}$, oppositely to $A$. deliciosa that present values in the order of $85 \mathrm{mg} / 100 \mathrm{~g} \mathrm{fw}$ (Ferguson \& Ferguson, 2003; Wojdyło et al., 2017).

\subsection{Phenolic profile identification by HPLC-DAD-MS}

Phenolic compounds are plants secondary metabolites with great importance for the nutritional and sensory quality of fruits and vegetables. The phenolic profile of plants is directly influenced by extrinsic and intrinsic factors, such as the stage of the plant development or the agronomic and environmental conditions during growth as well as genetic variability. Fig. 1 show the phenolic profile obtained for $A$. arguta and $A$. deliciosa decoctions and infusions. Table 4 summarize the different phenolic compounds identified and the relative percentage of each constituent expressed as percent of dry plant weight in the different samples.

According to Fig. 1(a) and (b) it is noteworthy that $A$. arguta extracts present a greater variability of phenolic compounds than $A$. deliciosa extracts. In what concerns to $A$. arguta, the phenolic composition of infusion and decoction is very similar. For both samples, quinic acid $(\mathrm{RT}=9.62 \mathrm{~min})$, cis-caftaric acid $(\mathrm{RT}=12.60 \mathrm{~min})$ and its derivatives $(\mathrm{RT}=27.65 \mathrm{~min})$, caffeoyl hexoside $(\mathrm{RT}=48.23 \mathrm{~min})$, luteolin glucuronide $(\mathrm{RT}=57.94 \mathrm{~min})$, quercetin derivatives $(\mathrm{TR}=85.81 \mathrm{~min}$ ) and myristin $(\mathrm{RT}=93.00 \mathrm{~min}$ ) are present (Table $4 \mathrm{a})$. Nevertheless, some compounds are present in the decoction and not in the infusion, such as caffeoylquinic acid ( $\mathrm{RT}=35.26 \mathrm{~min}$ ). According to Table 4 , the A. arguta infusion presented a higher relative amount of quinic acid and luteolin-glucuronide, followed by rutin/Q-3-ram-7-glc luteolin hexoside hexoside and quercetin-derivative. The other compounds are presented in higher amounts on decoction.

Regarding A. deliciosa, the phenolic profile of infusion and decoction (Fig. 1(c) and (d)) is very similar, presenting few compounds in their composition, namely quinic acid $(\mathrm{RT}=9.58 \mathrm{~min})$, caffeic acid 

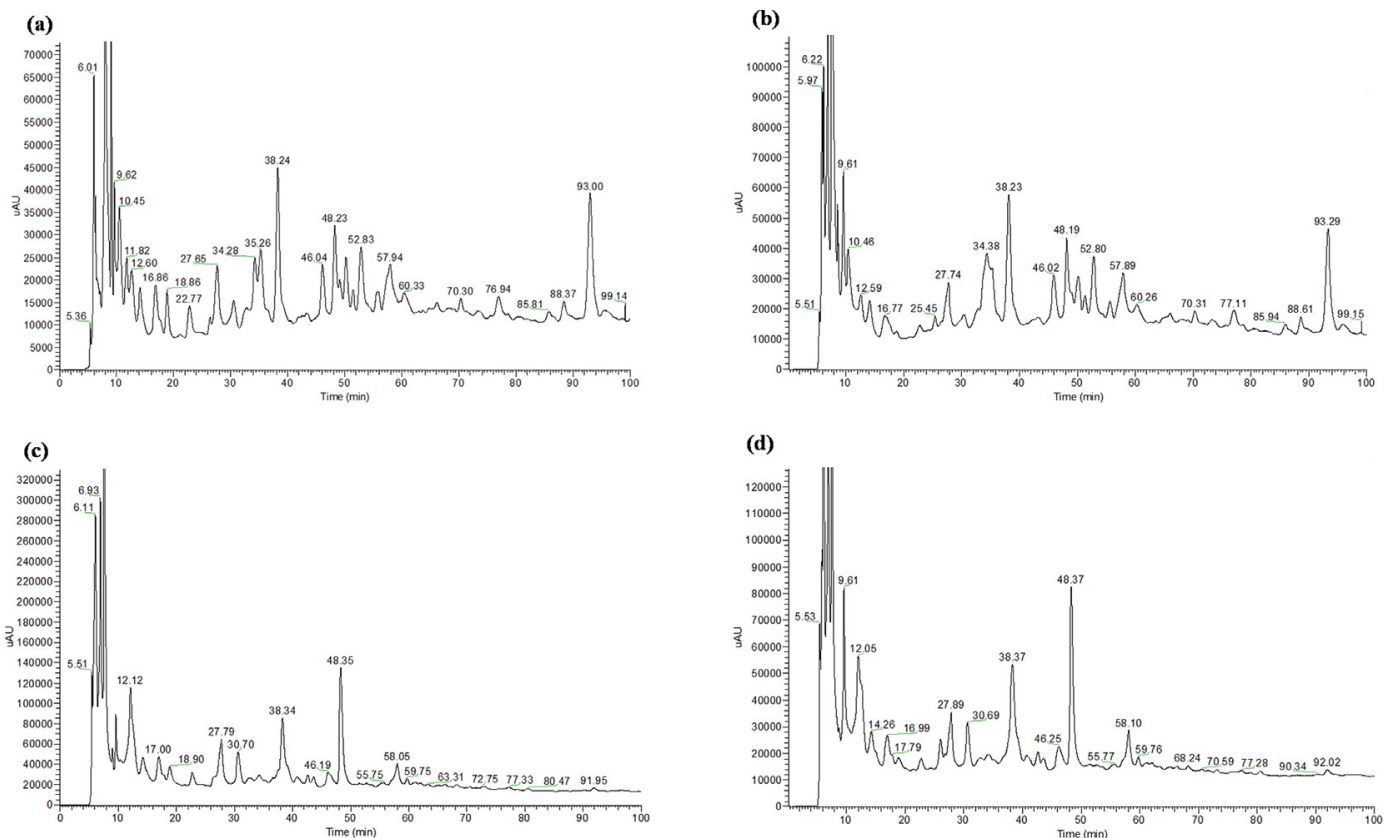

Fig. 1. Chromatographic profile of phenolic compounds obtained by HPLC-DAD-MS (280 nm) of (a) A. arguta decoction; (b) A. arguta infusion; (c) A. deliciosa decoction; (d) A. deliciosa infusion. Chromatographic conditions: see Table 4.

Table 4

Identification of the phenolic compounds from A. arguta (a) and A. deliciosa (b) infusions and decoctions by HPLC-DAD-MS. The \% area of tentatively identified compounds was determined at $280 \mathrm{~nm}$.

\begin{tabular}{|c|c|c|c|c|c|c|c|c|}
\hline \multicolumn{9}{|l|}{ A. arguta } \\
\hline \multicolumn{2}{|l|}{ Quinic acid } & 9.62 & 191.25 & $111.20 ; 172.87$ & & $256 ; 328$ & 1.64 & 2.66 \\
\hline & 10.45 & 628.87 & - & & 238; 271 & 3.14 & 2.58 \\
\hline \multirow{2}{*}{\multicolumn{2}{|c|}{$\begin{array}{l}\text { cis-Caftaric acid } \\
\text { Caffeic acid derivative }\end{array}$}} & 12.60 & 311.27 & - & & 232; 259 & 2.34 & 1.76 \\
\hline & & 27.65 & 563.14 & 341 (1 79) & & $247 ; 289$ & 2.82 & 2.19 \\
\hline \multicolumn{2}{|l|}{ Caffeoylquinic acid } & 35.26 & 353.45 & $190.87(-162)$ & & 325 & 3.11 & 1.99 \\
\hline \multicolumn{2}{|l|}{ Unknown } & 37.41 & 359.20 & $298.95(-60)$ & & - & 0.48 & 0.53 \\
\hline \multicolumn{2}{|l|}{ Caffeoyl hexoside } & 48.23 & 341.20 & 179 & & $253 ; 292 ; 316$ & 3.58 & 3.27 \\
\hline \multicolumn{2}{|l|}{ Caffeoylquinic acid } & 50.20 & 353.18 & - & & 325 & 2.83 & 2.41 \\
\hline \multicolumn{2}{|c|}{ Quercetin-pentoside-hexoside } & 55.78 & 595.14 & $355.27(-240) ; 385.13(-210)$ & $5.00(-120)$ & 292 & 2.17 & 1.90 \\
\hline \multicolumn{2}{|l|}{ Luteolin-glucuronide } & 57.94 & 461.22 & $400.93(-60)$ & & $259 ; 289 ; 322$ & 2.86 & 4.15 \\
\hline \multicolumn{2}{|l|}{ Quercetin-derivative } & 85.81 & 505.83 & - & & 325 & 0.63 & 1.33 \\
\hline Tentative identification & $\mathrm{RT}(\min )$ & \multicolumn{2}{|c|}{$[\mathrm{M}-\mathrm{H}]^{-}$} & $\mathrm{MS}^{2}$ & $\begin{array}{l}\lambda \\
(\mathrm{nm})\end{array}$ & \multicolumn{2}{|c|}{$\begin{array}{l}\text { Decoction } \\
\text { (Area fraction \%) }\end{array}$} & $\begin{array}{l}\text { Infusion } \\
\text { (Area fraction \%) }\end{array}$ \\
\hline \multicolumn{9}{|l|}{ (b) } \\
\hline Quinic acid & 9.58 & \multicolumn{2}{|c|}{383.07} & $191.00(111.13)$ & $253 ; 328$ & \multicolumn{2}{|l|}{1.75} & 2.25 \\
\hline Unknown & 12.12 & \multirow{2}{*}{\multicolumn{2}{|c|}{$\begin{array}{l}227.00 \\
371.20\end{array}$}} & 113.13 & $232 ; 256$ & \multicolumn{2}{|l|}{3.64} & 2.99 \\
\hline Unknown & 12.70 & & & - & $229 ; 259$ & \multirow{2}{*}{\multicolumn{2}{|c|}{$\begin{array}{l}2.80 \\
2.17\end{array}$}} & 2.64 \\
\hline Unknown & 13.75 & \multicolumn{2}{|c|}{629} & $436.73(-192)$ & - & & & 0.86 \\
\hline Unknown & 18.90 & & & 436.63 (332.73) & 292 & 2.19 & & 1.04 \\
\hline Unknown & 22.78 & & & $295.13(-1006)$ & 280 & 2.31 & & 1.21 \\
\hline Caffeic acid derivative & 27.79 & & & $341.00(179.07)$ & 289 & 4.34 & & 2.97 \\
\hline Caffeoyl hexoside & 38.34 & & & $179.13(-162)$ & $289 ; 316$ & 4.62 & & 5.33 \\
\hline Unknown & 48.35 & & & 179.13 (135.19) & 316 & 7.27 & & 6.73 \\
\hline Unknown & 58.19 & & & 179.13 (135.19) & - & 2.78 & & 2.72 \\
\hline
\end{tabular}


$(\mathrm{RT}=27.79 \mathrm{~min})$ and its derivatives and caffeoyl hexoside (RT $=38.34 \mathrm{~min}$ ) (Table $4 \mathrm{~b})$. The decoction showed higher amounts of caffeic acid derivative. Nevertheless, the presence of caffeic acid derivate and caffeoyl hexoside is higher in A. deliciosa extracts than in $A$. arguta.

It should be also highlighted the potential effect of decoction on the chemical modification of some constituents, which is probably due to the longer contact of the samples with the solvent during heating until boiling. Also, the highest antioxidant and radical scavenging activity observed for the decoction preparation may be responsible for the differences observed in Table 4.

Wojdyło et al. studied the phenolic profile of $5 \mathrm{~A}$. arguta and $2 \mathrm{~A}$. deliciosa cultivars (Wojdyło et al., 2017). The authors reported the presence of phenolic compounds, namely quercetin and kaempferol derivatives, quinic acid, caffeic $O$-hexoside acid, neochlorogenic acid, caffeoyl hexoside and chlorogenic acid in all samples (Wojdyło et al., 2017). These results are in line with the described in the present study. Park et al. evaluated the composition of different cultivars of $A$. chinensis kiwifruit, reporting the presence of protocatechuic acid, $p$-hydroxybenzoic acid, caffeic, vanillic, ferulic and anisic acid (Park et al., 2011). Recently, Almeida et al. analysed the phenolic profile of A. arguta leaves extracts (aqueous, hydroalcoholic and alcoholic), identifying caffeic acid, catechin, chlorogenic acid derivatives, quercetin derivatives and kaempferol derivatives as the major phenolic compounds (Almeida et al., 2018). The alcoholic extract was the richest (Almeida et al., 2018). Also, the present results are in line with Marangi et al. that using the Multi-Frequency Multimode Modulated Technology for extraction reported the presence of chlorogenic acid and glycosylated quercetin as well as kaempferol derivatives in A. arguta leaves (Marangi et al., 2018).

\subsection{Effects of extracts towards Caco-2 and HT29-MTX cells}

Caco-2 and HT29-MTX cell lines are frequently used as intestinal models to evaluate the effect of novel food ingredients on cell viability (de Francisco et al., 2018). The morphology and functional characteristics of Caco-2 are very similar to enterocytes, namely in tight junctions, apical and basolateral layers as well as in the microvilli present on the apical surface (Meunier, Bourrié, Berger, \& Fabre, 1995). In addition, the HT29-MTX cell line is indicated for digestion and bioavailability studies of food compounds (de Francisco et al., 2018).

The effects of $A$. arguta and $A$. deliciosa extracts was assessed on Caco-2 and HT29-MTX at concentrations ranging between 0.1 and
$1000 \mu \mathrm{g} / \mathrm{mL}$, through MTT assay. The LDH assay was also employed to evaluate the cytotoxicity. Table 5 summarizes the cell viability results.

As it is possible to observe, infusions and decoctions of both species did not lead to a decrease in the cellular viability of Caco-2 and HT29MTX, presenting results around $100 \%$. The statistical analysis showed that there are no significant differences $(p>0.05)$ in Caco-2 cell viability when exposure to $A$. deliciosa infusion and decoction (Table 5a). Nevertheless, the $A$. arguta decoction at $1000 \mu \mathrm{g} / \mathrm{mL}$ presented significant differences as well as the infusion at $1 \mu \mathrm{g} / \mathrm{mL}$ when compared to the other concentrations under study for this species.

When the viability of the different samples at the same concentration is analyzed, it is possible to observe differences $(p<0.05)$ between the $A$. arguta decoction and infusion as well as between the $A$. arguta infusion and the $A$. deliciosa infusion. Also, in the concentration of $100 \mu \mathrm{g} / \mathrm{mL}$, the decoctions of the different species were statistically different $(p<0.05)$. Similarly, at the concentration of $1000 \mu \mathrm{g} / \mathrm{mL}$ the two extractive methods of $A$. arguta revealed significant differences $(p<0.05)$. Nevertheless, it should be highlighted that any sample conducted to a decrease of Caco- 2 viability.

On the other hand, the statistical analysis to HT29-MTX cell line (Table $5 \mathrm{~b}$ ) showed that for the A. arguta decoction and the A. deliciosa infusion there are no differences between concentrations $(p>0.05)$.

In addition, according to the LDH assay, none of the samples led to toxicity in the cell lines used, being the results negative for all tested concentrations. These results were expected taking into account the cellular viability results.

Almeida et al. evaluated the effect of $A$. arguta leaves extracts on Caco-2 and HT29-MTX cells (Almeida et al., 2018). According to the results, the authors did not find a decrease on Caco-2 viability at all tested concentrations for the aqueous extract $(0.1-1000 \mu \mathrm{g} / \mathrm{mL})$. However, the hydroalcoholic and alcoholic extracts (at $1000 \mu \mathrm{g} / \mathrm{mL}$ ) conducted to a decrease in the cell viability to $58 \%$ and $60 \%$, respectively. For the HT29-MTX cell line, the authors did not find any decrease in cell viability for any of the extracts evaluated. Thus, it is possible to understand that the behaviour of the leaves in aqueous extract is very similar to the results reported in Table 5 .

\section{Conclusion}

The present work aimed to valorise the discarded fruits of $A$. arguta and $A$. deliciosa that do not present characteristics to be accepted for commercialization. Taking into account the current demand and interest of consumers for infusions and decoctions, this paper intended to

Table 5

Effects of A. arguta and A. deliciosa decoctions and infusions exposure on the viability of Caco-2 (a) and HT29-MTX (b) cells at different concentrations, as measured by the MTT assay. Values are expressed as mean \pm standard deviation $(n=6)$. Different numbers $(1,2,3)$ in the same species represent significant differences $(p<0.05)$ between different concentrations, according to Tukey's HSD test. Different letters (a,b,c) in the same concentration represent significant differences $(p<0.05)$ between species, according to Tukey's HSD test.

Concentration $(\mu \mathrm{g} / \mathrm{mL})$

\begin{tabular}{|c|c|c|c|c|c|}
\hline \multirow[b]{2}{*}{ Extract } & \multicolumn{5}{|c|}{ Concentration $(\mu \mathrm{g} / \mathrm{mL})$} \\
\hline & 0.1 & 1 & 10 & 100 & 1000 \\
\hline \multicolumn{6}{|l|}{ (a) } \\
\hline A. arguta decoction & $104.66 \pm 3.05^{2}$ & $111.88 \pm 1.32^{\mathrm{a}, \mathrm{b}, 2}$ & $106.32 \pm 8.91^{\mathrm{a}, \mathrm{b}, 2}$ & $110.83 \pm 5.23^{\mathrm{a}, \mathrm{b}, 2}$ & $127.94 \pm 5.61^{\mathrm{a}, 1}$ \\
\hline A. arguta infusion & $105.78 \pm 11.41^{2}$ & $107.33 \pm 5.78^{\mathrm{a}, 1}$ & $97.26 \pm 11.83^{\mathrm{b}, 2}$ & $101.50 \pm 3.59^{\mathrm{b}, 2}$ & $100.29 \pm 4.53^{\mathrm{c}, 2}$ \\
\hline A. deliciosa decoction & $117.07 \pm 6.05$ & $121.55 \pm 14.91^{\mathrm{a}}$ & $114.24 \pm 15.06^{\mathrm{a}}$ & $126.11 \pm 13.02^{\mathrm{a}}$ & $127.26 \pm 5.84^{\mathrm{a}}$ \\
\hline \multirow[t]{2}{*}{ A. deliciosa infusion } & $94.28 \pm 0.51$ & $101.71 \pm 12.11^{\mathrm{b}}$ & $110.33 \pm 5.50^{\mathrm{a}, \mathrm{b}}$ & $106.94 \pm 14.59^{\mathrm{b}}$ & $113.89 \pm 10.97^{b}$ \\
\hline & \multicolumn{5}{|c|}{ Concentration $(\mu \mathrm{g} / \mathrm{mL})$} \\
\hline Extract & 0.1 & 1 & 10 & 100 & 1000 \\
\hline \multicolumn{6}{|l|}{ (b) } \\
\hline A. arguta decoction & $106.17 \pm 8.35^{\mathrm{b}}$ & $109.25 \pm 18.20$ & $123.07 \pm 1.58^{\mathrm{a}}$ & $113.58 \pm 14.58$ & $126.63 \pm 8.54^{\mathrm{a}}$ \\
\hline A. arguta infusion & $123.67 \pm 3.70^{\mathrm{a}}$ & $119.40 \pm 4.16$ & $120.22 \pm 10.69^{\mathrm{a}}$ & $114.62 \pm 9.69$ & $110.68 \pm 16.05^{\mathrm{a}, \mathrm{b}}$ \\
\hline A. deliciosa decoction & $122.95 \pm 11.15^{\mathrm{a}}$ & $119.31 \pm 3.09$ & $103.63 \pm 10.16^{\mathrm{b}}$ & $124.56 \pm 15.88$ & $114.95 \pm 12.45^{\mathrm{a}, \mathrm{b}}$ \\
\hline A. deliciosa infusion & $102.30 \pm 8.11^{\mathrm{b}}$ & $116.04 \pm 14.15$ & $103.76 \pm 2.94^{\mathrm{b}}$ & $110.92 \pm 5.96$ & \\
\hline
\end{tabular}


prepare and characterize infusions and decoctions of dehydrated fruits of both species. The overall evaluation of this work allowed to conclude that $A$. arguta and $A$. deliciosa infusions and decoctions presented a high TPC and TFC as well as antioxidant activity. Nonetheless, the $A$. arguta decoction highlight these results, being considered the best option.

Similarly, in the HPLC-DAD-MS it was evident that $A$. arguta extracts had a greater variety of phenolic compounds in their composition. With regard to vitamin $\mathrm{C}$, the $A$. deliciosa infusion showed the highest content. In what concerns to ROS and RNS, a remarkable efficacy to scavenge these species was verified. In particular, the decoctions of the two species had a good ability to capture $\mathrm{HOCl}$ and NO. Regarding cell viability, all samples do not present possible adverse effects on Caco-2 and HT29-MTX cells in concentrations below $1000 \mu \mathrm{g} / \mathrm{mL}$. As major conclusion it is possible to infer that infusions and decoctions using dehydrated kiwiberry and kiwifruit can become a guarantee of success, coupled with a sustainable way of reducing waste. As main conclusion, it is possible to infer that $A$. arguta decoction presented the best results and could be considered the best option to keep the fruit benefits.

\section{Acknowledgments}

Diana Pinto is thankful for the research grant from project UID/ QUI/50006. Tânia Gonçalves Albuquerque is grateful for the $\mathrm{PhD}$ fellowship (SFRH/BD/99718/2014) funded by Foundation for Science and Technology. Francisca Rodrigues is thankful for her postdoc research grant from the project Operação NORTE-01-0145-FEDER000011. Iva Fernandes is grateful for the Post-Doctoral Grant SFRH/ BPD/86173/2012 from Foundation for Science and Technology. This work received financial support from the European Union (FEDER funds through COMPETE), under the Partnership Agreement PT2020, and National Funds (FCT, Foundation for Science and Technology) through project LAQV/UID/QUI/50006/2013 and NORTE-07-0124FEDER-000069 - Food Science.

\section{References}

Albuquerque, T. G., Santos, F., Sanches-Silva, A., Beatriz Oliveira, M., Bento, A. C., \& Costa, H. S. (2016). Nutritional and phytochemical composition of Annona cherimola Mill. fruits and by-products: Potential health benefits. Food Chemistry, 193, 187-195.

Almeida, D., Pinto, D., Santos, J., Vinha, A. F., Palmeira, J., Ferreira, H. N., ... Oliveira, M. B. P. P. (2018). Hardy kiwifruit leaves (Actinidia arguta): An extraordinary source of value-added compounds for food industry. Food Chemistry, 259, 113-121.

Alves, R., Costa, A., Jerez, M., Casal, S., Sineiro, J., Núñez, M., \& Oliveira, M. B. P. P. (2010). Antiradical activity, phenolics profile, and hydroxymethylfurfural in espresso coffee: Influence of technological factors. Journal of Agricultural and Food Chemistry, 58(23), 12221-12229.

Benzie, I. F. F., \& Strain, J. J. (1999). Ferric reducing/antioxidant power assay: Direct measure of total antioxidant activity of biological fluids and modified version for simultaneous measurement of total antioxidant power and ascorbic acid concentration. In P. Lester (Vol. Ed.), Methods in enzymology. Vol. 299. Methods in enzymology (pp. 15-27). Academic Press.

Barros, L., Baptista, P., \& Ferreira, I. C. F. R. (2007). Effect of Lactarius piperatus fruiting body maturity stage on antioxidant activity measured by several biochemical assays. Food and Chemical Toxicology, 45(9), 1731-1737.

D’Evoli, L., Moscatello, S., Lucarini, M., Aguzzi, A., Gabrielli, P., Proietti, S., ... LombardiBoccia, G. (2015). Nutritional traits and antioxidant capacity of kiwifruit (Actinidia deliciosa Planch., cv. Hayward) grown in Italy. Journal of Food Composition and Analysis, 37, 25-29.

de Francisco, L., Pinto, D., Rosseto, H., Toledo, L., Santos, R., Tobaldini-Valério, F., ... Rodrigues, F. (2018). Evaluation of radical scavenging activity, intestinal cell viability and antifungal activity of Brazilian propolis by-product. Food Research International, 105, 537-547.

EC (2011). Commission Implementing Regulation (EU) No 543/2011 of 7 June 2011 laying down detailed rules for the application of Council Regulation (EC) No 1234/ 2007 in respect of the fruit and vegetables and processed fruit and vegetables sectors. In E. Comission (Ed.), Official Journal of the European Union, vol. L 157).

Ferguson, A. R., \& Ferguson, L. R. (2003). Are kiwifruit really good for you? Acta Horticulturae, 610, 131-138.

Fernandes, A., Fernandes, I., Cruz, L., Mateus, N., Cabral, M., \& de Freitas, V. (2009).
Antioxidant and biological properties of bioactive phenolic compounds from Quercus suber L. Journal of Agricultural and Food Chemistry, 57(23), 11154-11160.

Gomes, A., Fernandes, E., Silva, A. M. S., Santos, C. M. M., Pinto, D. C. G. A., Cavaleiro, J. A. S., \& Lima, J. L. F. C. (2007). 2-Styrylchromones: Novel strong scavengers of reactive oxygen and nitrogen species. Bioorganic \& Medicinal Chemistry, 15(18), 6027-6036.

Guo, J., Yuan, Y., Dou, P., \& Yue, T. (2017). Multivariate statistical analysis of the polyphenolic constituents in kiwifruit juices to trace fruit varieties and geographical origins. Food Chemistry, 232, 552-559.

Gustavsson, J., Cederberg, C., Sonesson, R., van Otterdijk, R., \& Meybeck, A. (2011) Global foodlosses and food wastes: Extent, cause and prevention. Rome: Food and Agriculture Organization (FAO).

Henriques, J., Ribeiro, M. J., Falé, P. L., Pacheco, R., Ascensão, L., Florêncio, M. H., \& Serralheiro, M. L. M. (2017). Valorization of kiwifruit production: Leaves of the pruning branches of Actinidia deliciosa as a promising source of polyphenols. European Food Research and Technology, 243(8), 1343-1353.

Jiao, Y., Kilmartin, P. A., Fan, M., \& Quek, S. Y. (2018). Assessment of phenolic contributors to antioxidant activity of new kiwifruit cultivars using cyclic voltammetry combined with HPLC. Food Chemistry, 268, 77-85.

Kim, J. G., Beppu, K., \& Kataoka, I. (2009). Varietal differences in phenolic content and astringency in skin and flesh of hardy kiwifruit resources in Japan. Scientia Horticulturae, 120(4), 551-554.

Latocha, P. (2017). The nutritional and health benefits of kiwiberry (Actinidia arguta) - A review. Plant Foods for Human Nutrition (Dordrecht, Netherlands), 72(4), 325-334.

Latocha, P., Krupa, T., Wołosiak, R., Worobiej, E., \& Wilczak, J. (2010). Antioxidant activity and chemical difference in fruit of different Actinidia sp. International Journal of Food Sciences and Nutrition, 61(4), 381-394.

Latocha, P., Łata, B., \& Stasiak, A. (2015). Phenolics, ascorbate and the antioxidant potential of kiwiberry vs. common kiwifruit: The effect of cultivar and tissue type. Journal of Functional Foods, 19(Part A), 155-163.

Leontowicz, H., Leontowicz, M., Latocha, P., Jesion, I., Park, Y.-S., Katrich, E., .. Gorinstein, S. (2016). Bioactivity and nutritional properties of hardy kiwi fruit Actinidia arguta in comparison with Actinidia deliciosa 'Hayward' and Actinidia eriantha 'Bidan'. Food Chemistry, 196(Supplement C), 281-291.

Lv, H.-P., Zhang, Y., Shi, J., \& Lin, Z. (2017). Phytochemical profiles and antioxidant activities of Chinese dark teas obtained by different processing technologies. Food Research International, 100, 486-493.

Marangi, F., Pinto, D., Francisco, L., Alves, R. C., Puga, H., Sut, S., ... Oliveira, M. B. P. P. (2018). Hardy kiwi leaves extracted by multi-frequency multimode modulated technology: A sustainable and promising by-product for industry. Food Research International, 112, 184-191.

Mditshwa, A., Magwaza, L. S., Tesfay, S. Z., \& Opara, U. L. (2017). Postharvest factors affecting vitamin C content of citrus fruits: A review. Scientia Horticulturae, 218, 95-104.

Meunier, V., Bourrié, M., Berger, Y., \& Fabre, G. (1995). The human intestinal epithelial cell line Caco-2; pharmacological and pharmacokinetic applications. Cell Biology and Toxicology, 11(3), 187-194.

Nishiyama, I., Fukuda, T., Shimohashi, A., \& Oota, T. (2008). Sugar and organic acid composition in the fruit juice of different Actinidia varieties. Food Science and Technology Research, 14(1), 67-73.

Ou, B., Hampsch-Woodill, M., \& Prior, R. L. (2001). Development and validation of an improved oxygen radical absorbance capacity assay using fluorescein as the fluorescent probe. Journal of Agricultural and Food Chemistry, 49(10), 4619-4626.

Pacher, P., Beckman, J. S., \& Liaudet, L. (2007). Nitric oxide and peroxynitrite in health and disease. Physiological Reviews, 87(1), 315-424.

Park, Y. S., Leontowicz, H., Leontowicz, M., Namiesnik, J., Suhaj, M., Cvikrová, M., ... Gorinstein, S. (2011). Comparison of the contents of bioactive compounds and the level of antioxidant activity in different kiwifruit cultivars. Journal of Food Composition and Analysis, 24(7), 963-970.

Pénicaud, C., Peyron, S., Bohuon, P., Gontard, N., \& Guillard, V. (2010). Ascorbic acid in food: Development of a rapid analysis technique and application to diffusivity determination. Food Research International, 43(3), 838-847.

Pereira, C. G., Barreira, L., da Rosa Neng, N., Nogueira, J. M. F., Marques, C., Santos, T. F., ... Custodio, L. (2017). Searching for new sources of innovative products for the food industry within halophyte aromatic plants: In vitro antioxidant activity and phenolic and mineral contents of infusions and decoctions of Crithmum maritimum L. Food and Chemical Toxicology, 107, 581-589.

Pistón, M., Machado, I., Branco, C. S., Cesio, V., Heinzen, H., Ribeiro, D., ... Freitas, M. (2014). Infusion, decoction and hydroalcoholic extracts of leaves from artichoke (Cynara cardunculus L. subsp. cardunculus) are effective scavengers of physiologically relevant ROS and RNS. Food Research International, 64, 150-156.

Reddy, A., Norris, D. F., Momeni, S. S., Waldo, B., \& Ruby, J. D. (2016). The pH of beverages in the United States. The Journal of the American Dental Association, 147(4), 255-263.

Rodrigues, F., Palmeira-de-Oliveira, A., das Neves, J., Sarmento, B., Amaral, M. H., \& Oliveira, M. B. (2013). Medicago spp. extracts as promising ingredients for skin care products. Industrial Crops and Products, 49, 634-644.

Šavikin, K., Zdunić, G., Janković, T., Gođevac, D., Stanojković, T., \& Pljevljakušić, D. (2014). Berry fruit teas: Phenolic composition and cytotoxic activity. Food Research International, 62, 677-683.

Singleton, V. L., \& Rossi, J. A. J. (1965). Colorimetry of total phenolics with phosphomolybdic-phosphotungstic acid reagents. American Journal of Enology and Viticulture, 16, 144-158.

Spinola, V., Mendes, B., Camara, J. S., \& Castilho, P. C. (2012). An improved and fast UHPLC-PDA methodology for determination of L-ascorbic and dehydroascorbic acids in fruits and vegetables. Evaluation of degradation rate during storage. Analytical and 
Bioanalytical Chemistry, 403(4), 1049-1058.

Valente, A., Albuquerque, T. G., Sanches-Silva, A., \& Costa, H. S. (2011). Ascorbic acid content in exotic fruits: A contribution to produce quality data for food composition databases. Food Research International, 44(7), 2237-2242.

Wojdyło, A., Nowicka, P., Oszmiański, J., \& Golis, T. (2017). Phytochemical compounds and biological effects of Actinidia fruits. Journal of Functional Foods, 30, 194-202.

Zuo, L.-L., Wang, Z.-Y., Fan, Z.-L., Tian, S.-Q., \& Liu, J.-R. (2012). Evaluation of antioxidant and antiproliferative properties of three Actinidia (Actinidia kolomikta, Actinidia arguta, Actinidia chinensis) extracts in vitro. International Journal of Molecular Sciences, 13(5), 5506-5518. 